(c) 2021 Universidad Nacional Autónoma de México, Facultad de Estudios Superiores Zaragoza.

Este es un artículo Open Access bajo la licencia CC BY-NC-ND (http://creativecommons.org/licenses/by-nc-nd/4.0/).

TIP Revista Especializada en Ciencias Químico-Biológicas, 24: 1-15, 2021.

https://doi.org/10.22201/fesz.23958723e.2021.388

\title{
Estado actual de métodos alternativos, de control de hongos y su efecto en la calidad postcosecha de frutos de jitomate (Solanum lycopersicum)
}

\author{
Carlos A. Rodríguez-Guzmán', Beatriz Montaño-Leyva² ${ }^{2}$ Rita M. Velázquez-Estrada ${ }^{1}$, \\ Jorge A. Sánchez-Burgos ${ }^{1}$, María de Lourdes García-Magaña ${ }^{1}$, \\ Ramsés R. González-Estrada ${ }^{1}$ y Porfirio Gutiérrez-Martínez ${ }^{1 *}$ \\ ${ }^{1}$ Laboratorio Integral de Investigación en Alimentos/División de Estudios de Posgrado e Investigación, \\ Tecnológico Nacional de México/I. T. Tepic, Av. Tecnológico \#2595, Col. Lagos del Country, Tepic \\ 63175, Nayarit, México. ${ }^{2}$ Departamento de Investigación y Posgrado en Alimentos. Universidad de \\ Sonora, Encinas y Rosales s/n. Hermosillo, Sonora, 83000, México. E-mail: *pgutierrez@ittepic.edu.mx
}

\begin{abstract}
RESUMEN
Los tomates en la industria alimentaria son fundamentales por su sabor y alto valor nutricional. Para México, es de gran importancia económica por la generación de empleos directos e indirectos. Por esto la calidad postcosecha es fundamental, y puede verse alterada por condiciones como: temperatura, transporte y almacenamiento al provocar el desarrollo de hongos patógenos, que deterioran su calidad e impiden la comercialización del producto con pérdidas económicas. La principal estrategia de control son los fungicidas sintéticos, sin embargo, aunque son eficaces, afectan negativamente al medio ambiente y a los seres humanos al desarrollar cepas resistentes. Motivo por el que, los consumidores demandan constantemente productos seguros y sin residuos. Esta revisión muestra un panorama general de los métodos de control aplicados a los frutos de jitomate durante la etapa de postcosecha y plantea su aplicación, como una alternativa al uso de fungicidas, ellos son: los tratamientos térmicos, la luz ultravioleta, las sales orgánicas e inorgánicas, el quitosano, el metil jasmonato, el ácido salicílico, los extractos vegetales, los aceites esenciales y los microorganismos; considerados como sistemas ecológicos seguros y económicos que protegen contra los fitopatógenos, aumentan la vida útil y conservan la calidad de los frutos.
\end{abstract}

Palabras clave: antifúngico, ecoamigable, postcosecha, sustentable.

\section{Current status of alternative methods, of control of fungi and its effect on the post-harvest quality of tomato fruits (Solanum lycopersicum)}

\begin{abstract}
Tomatoes in food industry are essential for their flavor and high nutritional value. For Mexico, it is of great importance due to the spill economic and the generation of direct and indirect jobs. Therefore, post-harvest quality is essential, which can be influenced by conditions such as temperature, transport, and storage, causing the development of pathogenic fungi that deteriorate its quality and prevent its commercialization, generating economic losses. The primary control strategy is synthetic fungicides; However, although they are effective, they adversely affect the environment and humans and develop resistant strains. Because of this, consumers constantly demand safe and residue-free products. In this sense, this review shows a general overview of the control methods applied to tomato fruits during their post-harvest stage. Posing its application to the use of fungicides, such as heat treatments, ultraviolet light, organic and inorganic salts, chitosan, methyl jasmonate, salicylic acid, plant extracts, essential oils, and microorganisms; considering safe and economic ecological systems that protect against pathogens, increase shelf life and preserve fruit quality.
\end{abstract} Keywords: antifungal, ecofriendly, post-harvest, sustainable.

Artículo recibido el 22 de marzo del 2021.

Artículo aceptado el 09 de noviembre del 2021. 


\section{INTRODUCCIÓN}

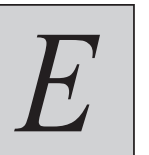

ljitomate es una de las hortalizas de mayor demanda a nivel mundial. Con un valor de poco más de 55 millones de dólares, ocupa el cuarto lugar entre los diez cultivos más importantes en términos de valor comercial en el mundo (Vincent et al., 2013). Para México, es una de las hortalizas de mayor producción, ocupa el primer lugar a nivel mundial en exportaciones (SIAP, 2019) y participa con el $2.4 \%$ de las 180 millones de toneladas que se producen en el mundo anualmente. (FAOSTAT, 2019). Sin embargo, una vez cosechado, la calidad y vida postcosecha del fruto, está condicionada por la temperatura, humedad relativa y otros factores que reducen su calidad y valor comercial.Además, estas condiciones favorecen la proliferación de hongos fitopatógenos como: (Alternaria alternata, Alternaria solani, Aspergillus niger, Aspergillus flavus, Colletotrichum lycoperssici, Colletotrichum sp., Rhizopus sp., Fusarium oxysporum, Botrytis cinerea, Penicillum digitatum, Cladosproium sp., entre otros) que atacan a los frutos durante su manejo postcosecha y ocasionan pérdidas económicas significativas (Arah, Amaglo, Kumah \& Ofori, 2015; Sajad \& Jamaluddin Abid, 2017; Rodrigues \& Kakde, 2019). Por lo tanto, el conocimiento y un diagnóstico adecuado de las enfermedades que afectan al jitomate durante la etapa postcosecha, son primordiales, para implementar tratamientos de control eficaces y alternativos al uso de fungicidas, (Xie, Tan \& Yu, 2012; Martínez-Ruiz et al., 2016; Arah, Ahorb, Anku, Kumah \& Amaglo, 2016). Actualmente, la estrategia de control que se utiliza, es la aplicación de fungicidas sintéticos, con un determinado nivel de eficacia, pero con efectos negativos en la salud humana y al medio ambiente; además de presentar problemas de resistencia a los patógenos, de aquí la tendencia en la búsqueda de tecnologías alternativas viables (Romanazzi et al., 2016a). Esta revisión presenta un panorama actual de las tecnologías alternativas al uso de fungicidas sintéticos para el control de enfermedades postcosecha en frutos de jitomate y como éstas impactan en parámetros relacionados a la calidad.

\section{FUNGICIDAS SINTÉTICOS EN POSTCOSECHA}

El uso de fungicidas sintéticos continúa siendo la estrategia dominante en el control de algunos hongos patógenos de frutas y hortalizas; en el caso de los frutos de jitomate no es la excepción, desde hace ya algunas décadas se ha reportado su uso en pre y postcosecha (Matyjaszczyk, 2015; Shamurailatpam \& Kumar, 2020), en donde fungicidas como Mancozeb y Azoxistrobina fueron aplicados en frutos de jitomate, a nivel in vivo y se observó una reducción del $50 \%$ de la lesión de la enfermedad ocasionada por Alternaria y Colletotrichum (Patel, Dange \& Patel, 2005; Chapin, Wang, Lutton \& Gardener, 2006). En una investigación más reciente, se utilizaron dosis de $220 \mathrm{~g} / \mathrm{L}$ de tiabendazol para controlar el moho gris causado por $B$. cinerea. Los resultados mostraron que 12 días después de la inoculación, se observó en los frutos control un deterioro del $100 \%$, mientras que en los frutos tratados con fungicida fue del 56.68\% (Shenglong, Jihong, Shaoyang, Shuang \& Li, 2019). Sin embargo, aun cuando se tienen resultados favorables en el control de los patógenos, su uso persistente e indiscriminado genera residuos tóxicos, nocivos para la salud a corto plazo (irritación de la piel y ojos, dolor de cabeza y náuseas) y a largo plazo (asma, diabetes y cáncer) (Ghazanfar et al., 2016; Kim, Kabir \& Jahan, 2017). Por lo que, el uso de fungicidas químicos como estrategia de control es cada día más cuestionable aunado a su falta de eficacia cuando las cepas patógenas desarrollan resistencia, lo que hace necesaria una investigación de nuevos fungicidas, sin embargo, la acción tiene un impacto en los costos de registro para su uso (Carvalho, 2006; Romanazzi, Smilanick, Feliziani \& Droby, 2016b). También es importante conocer el compuesto que se va a aplicar, al considerar varios aspectos como: el modo y sitio de acción, su límite máximo residual (LMR) permitido y las regulaciones para su exportación (Tabla I), además de las, estrategias para su uso racional, apoyándose en empresas de agroquímicos y centros de investigación (González-Estrada et al., 2019).

\section{Alternativas a los fUngicidas Sintéticos Para EL CONTROL DE ENFERMEDADES POSTCOSECHA DEL JITOMATE}

\section{Tratamientos térmicos}

Los tratamientos térmicos, son un método físico que ha demostrado efectos benéficos en la conservación de la calidad postcosecha, por el control del daño por frío y el control de la presencia de patógenos, son seguros para el ser humano y no generan daños al ambiente. Estos, pueden ser aplicados mediante el uso de agua caliente, aire caliente, vapor húmedo o cepillados con agua caliente. Generalmente, las temperaturas empleadas para los tratamientos con agua caliente oscilan entre $40-60{ }^{\circ} \mathrm{C} \mathrm{y}$ se manejan tiempos de 1 a 5 min, dependiendo del fruto a tratar (Sivakumar \& Fallik, 2013). También, los tratamientos térmicos han mostrado ser efectivos cuando se combinan con levaduras antagónicas, como la adición de Candida guilliermondii y Pichiamembranaefaciens, cuyos resultados mostraron un mayor efecto de control en la incidencia de $B$. cinerea. Además, el tratamiento térmico indujo la síntesis de enzimas como $\beta$-1,3Glucanasa (GLU), quitinasa (QUI) y fenilalanina amonio liasa (PAL) relacionadas con el sistema de defensa ante la presencia de hongos patógenos (Zong et al., 2010). De igual manera, los tratamientos con aire caliente en combinación con levaduras mostraron un efecto sinérgico, al reducir el desarrollo de la enfermedad causada por $B$. cinerea. Observándose un aumento en la inducción de las enzimas relacionadas con la defensa y la conservación de algunos parámetros de calidad (firmeza, sólidos solubles totales, acidez titulable), en comparación con el tratamiento térmico solo y el control (Wei et al., 2016). En ese sentido, algunos autores sugieren que la eficacia de los tratamientos térmicos puede deberse a que la temperatura podría inducir la producción de compuestos fenólicos y de enzimas antioxidantes, manteniendo la calidad del fruto. Por lo que, el efecto de los tratamientos térmicos está relacionado con los tiempos de exposición y el método de aplicación (Tabla II). 
Tabla I. Generalidades de los fungicidas químicos utilizados en frutos de jitomate.

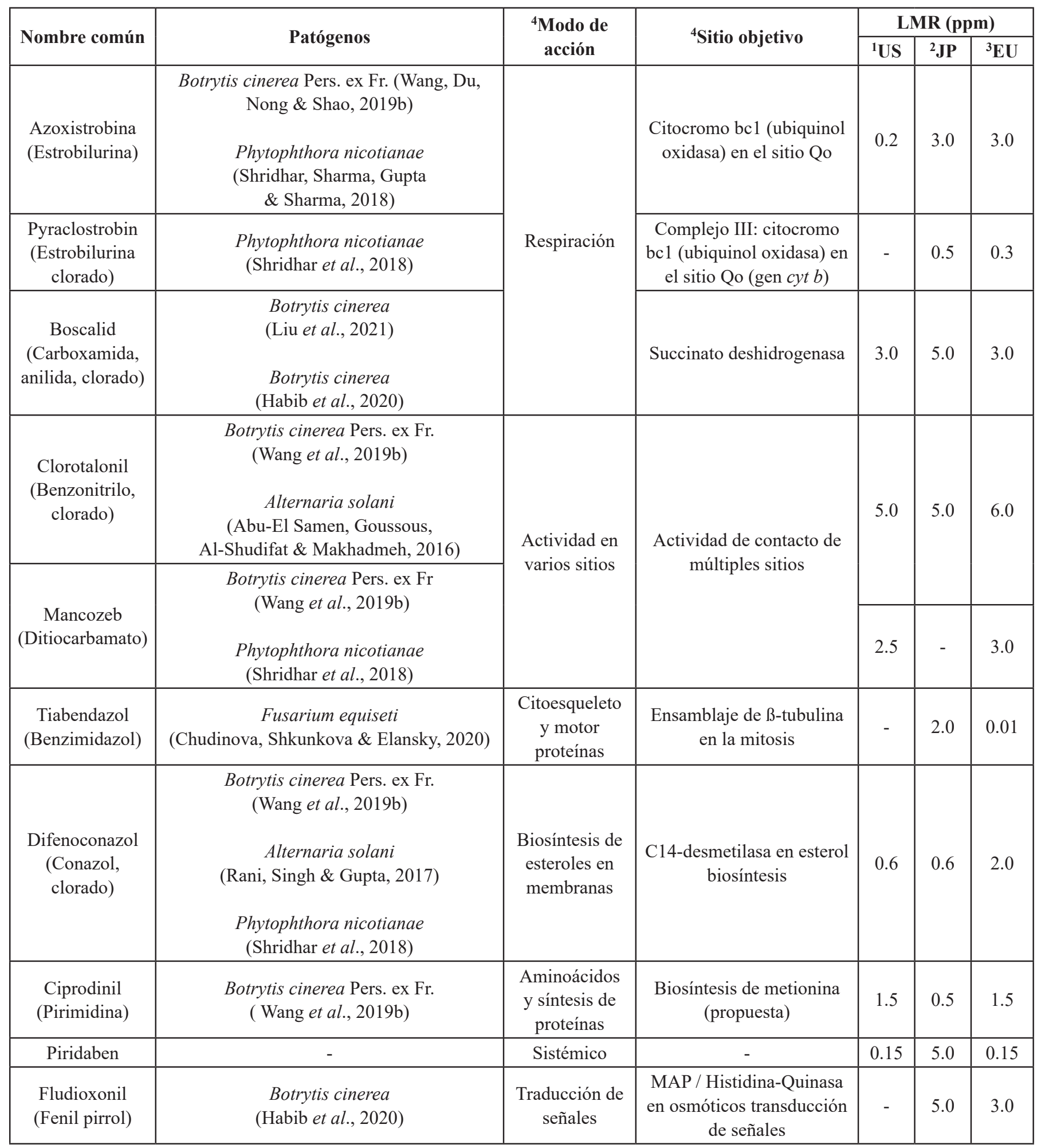

${ }^{1}$ Electronic Code of Federal Regulations, ${ }^{2}$ The Japan Food Chemical Research Foundation ${ }^{3}$ European Commission, ${ }^{4}$ FRAC. Fungicide Resistance Action Commitee, (-) No disponible, 2020. 
Tabla II. Efecto de los tratamientos térmicos en frutos de jitomate.

\begin{tabular}{|c|c|c|c|}
\hline $\begin{array}{l}\text { Método de } \\
\text { aplicación }\end{array}$ & Condiciones & Resultados & Referencias \\
\hline $\begin{array}{l}\text { Inmersión en } \\
\text { agua }\end{array}$ & $\begin{array}{c}52^{\circ} \mathrm{C} \text { por } 15 \mathrm{~min} \\
\text { A } 20^{\circ} \mathrm{C} \text { de } 0-4 \text { días }\end{array}$ & $\begin{array}{c}\text { Aumento de la capacidad antioxidante: } \\
\text { catalasa y peroxidasa }\end{array}$ & $\begin{array}{l}\text { (Imahori, Bai \& } \\
\text { Baldwin, 2016) }\end{array}$ \\
\hline $\begin{array}{l}\text { Inmersión en } \\
\text { agua }\end{array}$ & $\begin{array}{c}55^{\circ} \mathrm{C} \text { por } 7 \mathrm{~min} \\
\text { A } 13^{\circ} \mathrm{C} \text { por } 3 \text { semanas }\end{array}$ & $\begin{array}{l}\text { Inhibición del desarrollo de Alternaria alternata, } \\
\text { Botryits cinerea y Geotrichum candidum } \\
\text { Aumento de sólidos solubles totales y firmeza } \\
\text { Disminución de la pérdida de peso }\end{array}$ & $\begin{array}{l}\text { (Yasser, Marzouk, } \\
\text { Kamel \& Naaffa, } \\
\text { 2019) }\end{array}$ \\
\hline $\begin{array}{l}\text { Inmersión en } \\
\text { agua }\end{array}$ & $\begin{array}{l}40^{\circ} \mathrm{C} \text { por } 20 \text { min } \\
\text { A } 4^{\circ} \mathrm{C} \text { por } 16 \text { días }\end{array}$ & $\begin{array}{c}\text { Conserva los parámetros de calidad } \\
\text { Reducción del daño por frío } \\
\text { Mayor vida de anaquel }\end{array}$ & $\begin{array}{l}\text { (Tadesse \& Abtew, } \\
\text { 2016) }\end{array}$ \\
\hline $\begin{array}{l}\text { Inmersión en } \\
\text { agua }\end{array}$ & $\begin{array}{l}40 \text { y } 60{ }^{\circ} \mathrm{C} \text { por } 20 \text { semanas } \\
\text { A temperatura ambiente por } \\
3,6 \text { y } 10 \text { días }\end{array}$ & Control de la infección por Rhizopus stolonifer & $\begin{array}{l}\text { (Alfaro-Sifuentes } \\
\text { et al., 2019) }\end{array}$ \\
\hline Aire caliente & $\begin{array}{l}38^{\circ} \mathrm{C} \text { por } 12 \text { horas } \\
\mathrm{A} 20^{\circ} \mathrm{C} \text { por } 15 \text { días }\end{array}$ & $\begin{array}{c}\text { Reducción de la actividad de las enzimas } \\
\text { relacionadas con la degradación de la pared celular: } \\
\text { celulasa, poligalacturonasa, } \beta \text {-Galactosidasa y pectín } \\
\text { metilesterasa } \\
\text { Reducción de la tasa respiratoria y producción de } \\
\text { etileno }\end{array}$ & (Wei et al., 2018) \\
\hline $\begin{array}{l}\text { Inmersión en } \\
\text { agua }\end{array}$ & $\begin{array}{c}52^{\circ} \mathrm{C} \text { por } 5 \text { min } \\
\text { A } 20,12.5 \text { y } 5^{\circ} \mathrm{C} \text { por } 1 \text { o } 2 \\
\text { semanas }\end{array}$ & $\begin{array}{c}\text { Reducción de daño por frío } \\
\text { Aumento de la capacidad antioxidante } \\
\text { Aumento de los compuestos fenólicos: } \\
\text { Carotenoides y licopeno }\end{array}$ & $\begin{array}{c}\text { (Loayza et al., } \\
2020)\end{array}$ \\
\hline $\begin{array}{c}\text { Termo- } \\
\text { sonicación }\end{array}$ & $\begin{array}{l}32-40{ }^{\circ} \mathrm{C} \text { por } 13-47 \mathrm{~min} \\
\text { Frecuencia } 45 \mathrm{kHz} \text { y } 80 \% \text { de } \\
\text { potencia } \\
\text { A } 10{ }^{\circ} \mathrm{C} \text { De } 1-15 \text { días }\end{array}$ & $\begin{array}{c}\text { Reducción del proceso de maduración } \\
\text { Conservación de los parámetros de calidad (color, } \\
\text { firmeza, contenido total de fenoles y pérdida de } \\
\text { peso). }\end{array}$ & $\begin{array}{l}\text { (Pinheiro, Ganhao, } \\
\text { Goncalves \& } \\
\text { Silva, 2019) }\end{array}$ \\
\hline $\begin{array}{l}\text { Inmersión en } \\
\text { agua }\end{array}$ & $\begin{array}{l}40^{\circ} \mathrm{C} \text { por } 10 \text { min } \\
\text { A } 4{ }^{\circ} \mathrm{C} \text { por } 21 \text { días }\end{array}$ & $\begin{array}{c}\text { Reducción del daño por frío en un } 50 \% \\
\text { Reducción de la pérdida de la actividad antioxidante } \\
\text { en más del } 50 \% \text {. }\end{array}$ & $\begin{array}{l}\text { (Singh, Roy, } \\
\text { Mishra \& Garg, } \\
\text { 2020) }\end{array}$ \\
\hline $\begin{array}{l}\text { Inmersión en } \\
\text { agua }\end{array}$ & $52^{\circ} \mathrm{C}$ por $5 \mathrm{~min}$ & Compuestos volátiles & $\begin{array}{l}\text { (Wang et al., } \\
\text { 2019a) }\end{array}$ \\
\hline $\begin{array}{l}\text { Inmersión en } \\
\text { agua }\end{array}$ & $\begin{array}{l}40^{\circ} \mathrm{C} \text { por } 10 \mathrm{~min} \\
\mathrm{~A} 13^{\circ} \mathrm{C} \text { por } 20 \text { días }\end{array}$ & $\begin{array}{c}\text { Reducción del } 54.8 \% \text { del deterioro del fruto } \\
\text { Aumento de la actividad enzimática de la catalasa y } \\
\text { peroxidasa } \\
\text { Conservación de los parámetros de calidad: } \\
\text { Sólidos solubles totales, acidez titulable, ácido } \\
\text { ascórbico y pérdida de peso }\end{array}$ & (Boonkorn, 2016) \\
\hline
\end{tabular}




\section{Tratamientos UV-C}

La aplicación de tratamientos basados en UV-C han sido utilizados en el control de patógenos y en la conservación de la calidad durante la etapa postcosecha de una amplia variedad de frutos y hortalizas (Tabla III) (Zhang \& Jiang, 2019); el resultado se ve en un estudio realizado con frutos de jitomate y la aplicación de un tratamiento con UV-C, una dosis de $4.2 \mathrm{~kJ} / \mathrm{m}^{-2}$ por 8 min y posteriormente almacenados a $18{ }^{\circ} \mathrm{C}$ durante 35 días. Los datos obtenidos evidenciaron una menor producción de etileno hasta el día 25 , respecto al control. Además, de la reducción en la actividad de algunas enzimas (pectin metilesterasa, poligaracturonasa y celulasa) relacionadas con la degradación de la pared celular, lo que provocó un incremento de su vida de anaquel $(\mathrm{Bu}, \mathrm{Yu}$, Aisikaer \& Ying, 2013). De igual manera cuando se aplicaron dosis de $4.1 \mathrm{~kJ} / \mathrm{m}^{2}$ y almacenados a $20{ }^{\circ} \mathrm{C}$ por 12 días, se observó una reducción de la producción de etileno y enzimas como la pectin metil esterasa y poligaracturonasa, conservándose la calidad de los frutos por más tiempo (Lu, Li, Limwachiranon, Xie \& Luo, 2016). Así mismo, se ha observado un aumento de compuestos benéficos para la salud como los antioxidantes (licopeno, carotenoides y compuestos fenólicos); sin alterar los atributos sensoriales de los frutos durante el almacenamiento por 21 días a $20^{\circ} \mathrm{C}$ (Pataro, Sinik, Capitoli, Donsì \& Ferrari, 2015). Esto sugiere, que los tratamientos con UV-C aplicados a los frutos de jitomate tienen un efecto en el aumento del potencial antioxidante, inducción de los mecanismos de defensa, conservación de atributos sensoriales y del valor nutricional (Mditshwa, Magwaza, Tesfay \& Mbili, 2017). También, autores como (Tauxe, 2001; Shama \& Alderson, 2005) proponen que el mecanismo de acción de los tratamientos con UV puede ser de dos formas: una mediante la alteración de la cadena del DNA, provocando que el hongo sea incapaz de desarrollarse y la segunda mediante la inducción de compuestos antifúngicos y de enzimas relacionadas con la defensa del fruto.

\section{Sales orgánicas e inorgánicas}

Las sales orgánicas e inorgánicas son sustancias químicas consideradas como aditivos y reconocidas como seguras, por sus siglas inglés "Generally Recognised As Safe" (GRAS), presentan atributos como gran disponibilidad, fácil manejo y de bajo costo. Actualmente son de uso común en la industria alimentaria, son de baja toxicidad y pueden combinarse con otros sistemas para el control de enfermedades en frutos y hortalizas como el jitomate durante su etapa postcosecha (Palou, Ali, Fallik \& Romanazzi, 2016). Asimismo, la aplicación de sales como el sorbato de potasio, es utilizado en concentraciones bajas $(0.1 \%)$ para el control de los patógenos que se presentan en los frutos de jitomate. Observándose un efecto en la reducción de la pudrición por B. cinerea, Rhizoctonia, Alternaria solani y Colletotrichum coccodes en un porcentaje de 30.81, 15.74, 31.67 y $25.24 \%$ respectivamente (Jabnoun-Khiareddine et al., 2016). En el caso del carbonato de potasio, silicato, carbonato y bicarbonato de sodio, mostraron un efecto sobre el control de la incidencia y severidad de la enfermedad ocasionada por $B$. cinerea, a una concentración de 200 y 300 mM (Alaoui, Askarne, Boubaker, Boudyach \& Aoumar, 2017). También, el carbonato de potasio, propionato de sodio, carbonato y fosfato de amonio; mostraron una reducción de la severidad de la enfermedad ocasionada por B. cinerea, cuando fueron almacenados por 14 días a $5{ }^{\circ} \mathrm{C}$, más 7 días a $20^{\circ} \mathrm{C}$. En cuanto a la incidencia de la enfermedad, sólo se observó el efecto hasta el día 14 (Fagundes, Palou, Monteiro \& Pérez-Gago, 2014). Así mismo, se ha reportado que sales como el benzoato de sodio en combinación con cera de abeja muestran un efecto reductor en la severidad e incidencia de la enfermedad causada por Alternaria alternata, sobre frutos de jitomate almacenados a $5{ }^{\circ} \mathrm{C}$ por 21 días, más 4 días a $20^{\circ} \mathrm{C}$ (Fagundes, Palou, Monteiro \& Pérez-Gago, 2015). Además, un estudio reciente utilizó nanopartículas de sal de amonio en concentraciones de 0.1 y $0.2 \mathrm{mM}$ como tratamientos para el control del moho negro y moho verde ocasionados por $A$. alternata y Penicillium digitatum, mostrando un porcentaje de eficacia sobre la severidad de la enfermedad mayor del 70 y $60 \%$ respectivamente, así como, más del $60 \%$ en los frutos inoculados naturalmente (Abdel-Rahman; Rashid \& Shoala, 2020). Por lo que, uno de los principales mecanismos que se le atribuyen a las sales es su efecto inhibidor, por la acción directa de la sal contra el patógeno que consiste en la alcalinización del sitio de infección, provocando una reducción de la virulencia de algunos patógenos (Venditti et al., 2018). Por otro lado, se han reportado mecanismos de defensa propios del fruto, por inducción de enzimas como GLU, peroxidasa (POD) y PAL, relacionadas con el control de patógenos (Youssef, Sanzani, Ligorio, Ippolito \& Terry, 2014). El hecho de que existan pocos estudios de sales orgánicas e inorgánicas en frutos de jitomate, abre la posibilidad de nuevas investigaciones, en donde se evalúen aspectos microbiológicos y calidad del fruto.

\section{Quitosano}

El quitosano, es un polímero natural, no tóxico y biodegradable, ha sido utilizado en el control postcosecha de una gran variedad de frutas y hortalizas (Duan et al., 2019). Su efectividad está relacionada con propiedades antifúngicas, inducción de mecanismos de defensa en frutos tratados y como barrera de protección por su capacidad de formar películas (Romanazzi, Feliziani \& Sivakumar, 2018). Así mismo, puede utilizarse solo o en combinación con otros sistemas de control en la etapa de precosecha y postcosecha (Bautista-Baños, VenturaAguilar, Correa-Pacheco \& Corona-Rangel, 2017; GutiérrezMartínez et al., 2018; Rodríguez-Guzmán, González-Estrada, Bautista-Baños \& Gutiérrez-Martínez, 2019). Se ha reportado que la actividad antifúngica del quitosano consiste en alterar la permeabilidad de la membrana microbiana a través de interacciones con las superficies celulares fúngicas, provocando un desequilibrio osmótico y la liberación de macromoléculas para procesos bioquímicos vitales para su desarrollo, hasta lisis celular (Guo, Qiao, Ji, Wang \& Zhu, 2020). En cuanto a su propiedad de barrera se debe a su capacidad de formar 
Tabla III. Efecto de los tratamientos con UV-C sobre los parámetros de calidad de los frutos de jitomate.

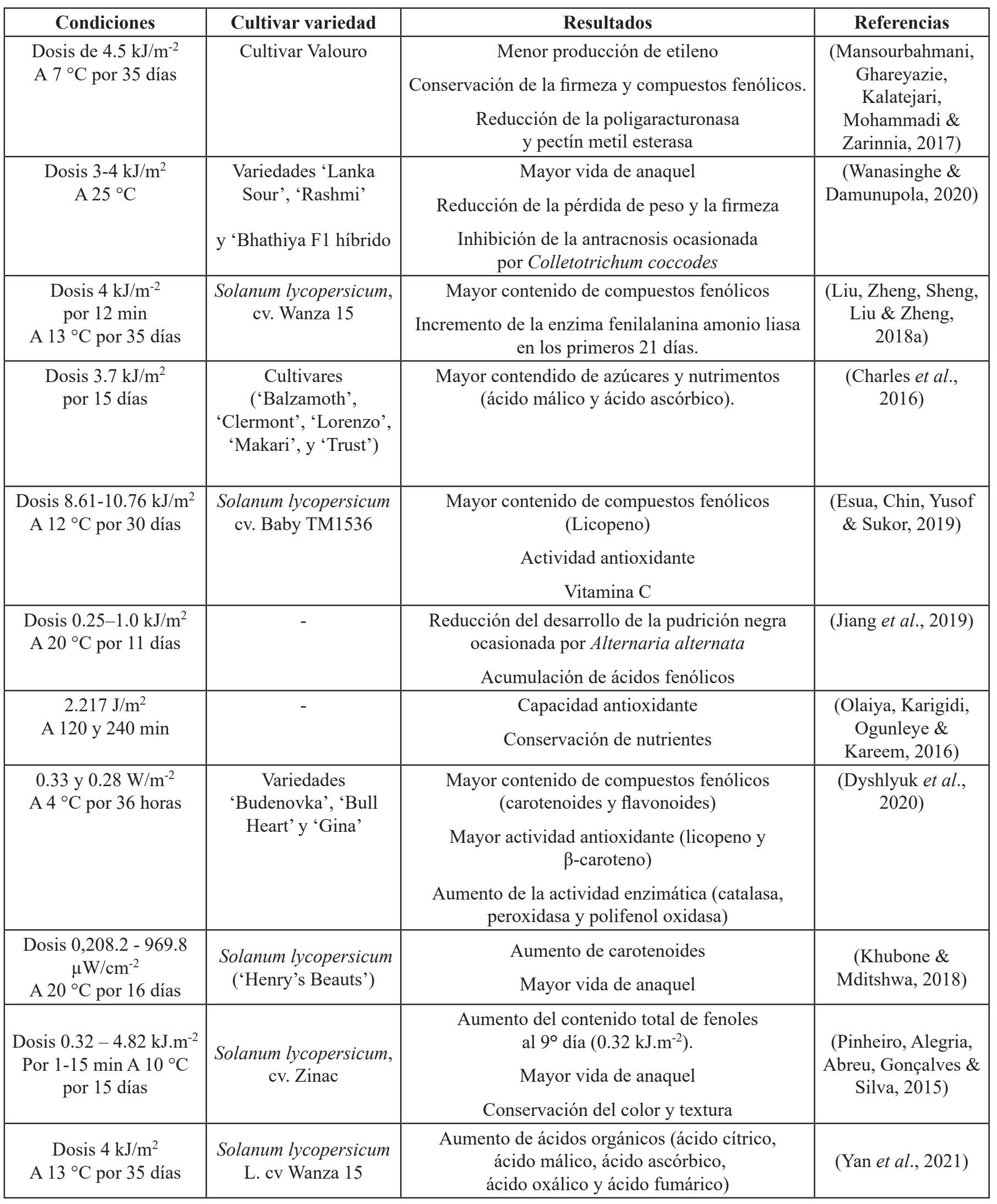


recubrimientos cuando es aplicado en frutas y hortalizas y contribuye al proceso de conservación de la calidad del fruto tratado (Xing et al., 2016), aunado a la capacidad de inducir una mayor resistencia ante el estrés biótico o abiótico (Romanazzi, Feliziani, Baños \& Sivakumar, 2017). Por lo tanto, el quitosano solo o en combinación puede ser una herramienta prometedora contra el deterioro de los frutos de jitomate en postcosecha Tabla IV (Manigandan, Karthik, Ramachandran \& Rajagopal, 2018).

\section{Ácido salicílico y Metil jasmonato}

El ácido salicílico y el metil jasmonato son compuestos producidos de forma endógena por las plantas, y actúan como un regulador de la señalización para acciones como el crecimiento y el desarrollo en las plantas. Se ha demostrado que aplicados de forma exógena pueden tener un efecto antifúngico sobre los hongos patógenos en la etapa de postcosecha de cultivos hortícolas (Poveda, 2020). Por esto, los frutos de jitomate

Tabla IV. Estudios del efecto del quitosano sobre frutos de jitomate.

\begin{tabular}{|c|c|c|c|}
\hline $\begin{array}{c}\text { Características } \\
\text { Quitosano }\end{array}$ & Combinaciones & Resultados & Referencias \\
\hline $\begin{array}{l}\text { Peso molecular } \\
\text { medio peso } \\
\text { molecular } \\
(\text { Grado } \\
\text { desacetilación } \\
89 \%)\end{array}$ & $\begin{array}{l}\text { Quitosano } 1.0 \% \\
\text { Cera de abeja } 0.1 \% \\
\text { Aceite esencial de } \\
\text { orégano }(0.005,0.03 \\
\text { y } 0.01 \%) \\
\text { Ácido acético } 0.1 \%\end{array}$ & $\begin{array}{l}\text { Conservación de los parámetros de calidad (Firmeza y } \\
\text { carotenoides). } \\
\text { Reducción de la producción de los parámetros fisiológicos (etileno, } \\
\text { tasa de respiración y peso). } \\
\text { Reducción de la incidencia y severidad de los hongos (Alternaria } \\
\text { sp., Cladosporium sp., Fusarium sp. y Botrytis sp.). }\end{array}$ & \begin{tabular}{|l} 
(Rives- \\
Castillo, \\
Ventura- \\
Aguilar, \\
Hernández- \\
López \& \\
Bautista-Baños \\
2018) \\
\end{tabular} \\
\hline $\begin{array}{l}\text { Peso molecular } \\
\text { medio (Grado } \\
\text { desacetilación } \\
75-85 \% \text { ) }\end{array}$ & $\begin{array}{c}\text { Quitosano }(4 \mathrm{mg} / \\
\mathrm{mL}) \\
\text { Cymbopogon } \\
\text { citratus }(\mathrm{Dc} . \mathrm{Ex} \\
\text { Nees })(1.25 \mu \mathrm{L} / \mathrm{mL}) \text {. }\end{array}$ & $\begin{array}{c}\text { Reducción de la severidad de la pudrición blanda por } R \text {. stolonifer } \\
\text { hasta el día } 6 . \\
\text { Conservación de los parámetros sensoriales } \\
\text { al día } 8 \text { (Color y sabor). }\end{array}$ & $\begin{array}{l}\text { (Athayde et al., } \\
\text { 2016) }\end{array}$ \\
\hline $\begin{array}{l}\text { Peso molecular } \\
\text { alto (Grado } \\
\text { desacetilación } \\
91.23 \% \text { ) }\end{array}$ & $\begin{array}{l}\text { Quitosano } 0.6 \% \\
\text { Alginato } 0.2 \% \\
\text { Flourensia cernua } \\
\quad\left(5,000 \mathrm{mg} \mathrm{L}^{-1}\right)\end{array}$ & $\begin{array}{l}\text { Conservación de los parámetros de calidad (pérdida de peso, } \\
\text { firmeza y color). } \\
\text { Inhibición de la presencia de microorganismos al día 6. (hongos, } \\
\text { levaduras y microorganismos mesófilos aeróbicos). } \\
\text { Extensión de la vida de anaquel a } 9 \text { días más. }\end{array}$ & $\begin{array}{l}\text { (Salas-Méndez } \\
\text { et al., 2019) }\end{array}$ \\
\hline Sigma & $\begin{array}{l}\text { Quitosano } \\
1,000 \mathrm{ppm}\end{array}$ & $\begin{array}{l}\text { Reducción del deterioro del fruto en un } 88 \% \text { al día } \\
\qquad 8 \text { respecto al control. }\end{array}$ & $\begin{array}{l}\text { (Sharif, Kumer, } \\
\text { Ahmed \& Paul, } \\
\text { 2018) }\end{array}$ \\
\hline $\begin{array}{l}\text { Peso molecular } \\
\text { bajo (Grado de } \\
\text { desacetilación } \\
\quad 75-85 \% \text { ) }\end{array}$ & $\begin{array}{c}\text { Quitosano } \\
(0.5,1.0 \text { y } 1.5 \%)\end{array}$ & $\begin{array}{l}\text { Reducción de la pérdida de peso a temperatura ambiente } 21^{\circ} \mathrm{C} \text { y } \\
\text { de refrigeración } 5{ }^{\circ} \mathrm{C} \text { durante } 10 \text { días. } \\
\text { Conservación del total de fenoles y actividad antioxidante durante } \\
\text { el almacenamiento a } 5^{\circ} \mathrm{C}\end{array}$ & $\begin{array}{l}\text { (Kibar \& Sabir, } \\
\text { 2018) }\end{array}$ \\
\hline $\begin{array}{l}\text { Sisco Research } \\
\text { Laboratories }\end{array}$ & $\begin{array}{c}\text { Quitosano } \\
(0.25 \text { y } 0.5 \%)\end{array}$ & $\begin{array}{l}\text { Reducción de la pérdida de peso y la humedad } \\
\text { a los } 30 \text { días de almacenamiento } \\
\text { Conservación de los sólidos solubles totales durante } 30 \text { días a } 6{ }^{\circ} \mathrm{C}\end{array}$ & $\begin{array}{l}\text { Sucharitha, } \\
\text { Beulah \& } \\
\text { Ravikiran, } \\
\text { 2018) }\end{array}$ \\
\hline $\begin{array}{l}\text { Galeno Sr., } \\
\text { Carmignano, } \\
\text { Prato, Italy }\end{array}$ & Quitosano 1.5\% & $\begin{array}{l}\text { Mayor vida de anaquel de } 3 \text { a } 4 \text { días más. } \\
\text { (Reducción de la producción de etileno en los días 7-11) } \\
\text { (Reducción de la pérdida de peso y la firmeza al día 14) } \\
\text { Conservación de los parámetros de calidad } \\
\text { ( } \beta \text {-caroteno y licopeno). }\end{array}$ & $\begin{array}{c}\text { (Pagno et al., } \\
\text { 2018). }\end{array}$ \\
\hline
\end{tabular}


Tabla IV. Estudios del efecto del quitosano sobre frutos de jitomate.

\begin{tabular}{|c|c|c|c|}
\hline $\begin{array}{c}\text { Características } \\
\text { Quitosano }\end{array}$ & Combinaciones & Resultados & Referencias \\
\hline- & $\begin{array}{c}\text { Quitosano }(0.5,1.0 \\
2.0 \text { y } 2.5 \%)\end{array}$ & $\begin{array}{l}\text { Mayor vida de anaquel por } 10 \text { días más. } \\
\text { Conservación de los parámetros de calidad (acidez titulable, } \mathrm{pH} \text {, } \\
\text { sólidos solubles totales, firmeza y licopeno). }\end{array}$ & $\begin{array}{l}\text { (Sree, Sree } \\
\& \text { Samreen, } \\
2020)\end{array}$ \\
\hline $\begin{array}{l}\text { Department of } \\
\text { Agricultural } \\
\text { Chemistry, } \\
\text { BAU, } \\
\text { Mymensingh }\end{array}$ & $\begin{array}{c}\text { Quitosano }(0.1,0.2 \\
\text { y } 0.3 \%)\end{array}$ & $\begin{array}{l}\text { Mayor vida de anaquel a temperatura ambiente y a } 4{ }^{\circ} \mathrm{C} \\
\text { en un } 40 \text { y } 50 \% \text { respectivamente. } \\
\text { Reducción de la pérdida de peso }\end{array}$ & $\begin{array}{l}\text { (Sultana, } \\
\text { Zakir, Parvin, } \\
\text { Sharmin \& } \\
\text { Seal, 2019) }\end{array}$ \\
\hline- & $\begin{array}{c}\text { Quitosano }(1.0,1.5 \\
\text { y } 2.0 \%)\end{array}$ & $\begin{array}{c}\text { Mayor vida de anaquel por } 7 \text { días más. } \\
\text { Conservación de la firmeza, pérdida de peso. } \\
\text { Reducción del deterioro del fruto hasta un } 24 \% \text { respecto al control. }\end{array}$ & $\begin{array}{c}\text { (Mandal \& } \\
\text { Shukla, 2018) }\end{array}$ \\
\hline $\begin{array}{l}\text { Peso molecular } \\
\text { alto (Grado de } \\
\text { desacetilación } \\
\quad 79 \%)\end{array}$ & $\begin{array}{c}\text { Quitosano }(1,500 \mathrm{y} \\
2,000 \mathrm{ppm})\end{array}$ & $\begin{array}{c}\text { Conservación de la vida de anaquel por } 4 \text { semanas } \\
\text { más respecto al control } \\
\text { Reducción de la presencia de microorganismos después de } 3 \\
\text { semanas de almacenamiento }\end{array}$ & $\begin{array}{l}\text { (Parvin, Kader, } \\
\text { Huque, Molla } \\
\text { \& Khan, 2018) }\end{array}$ \\
\hline $\begin{array}{l}\text { Hi-Media } \\
\text { Laboratories } \\
\text { (Mumbai, India) }\end{array}$ & $\begin{array}{l}\text { Quitosano }(1.0 \mathrm{y} \\
2.0 \%) \\
\text { Aloe vera }(1.0 \mathrm{y} \\
2.0 \%)\end{array}$ & $\begin{array}{c}\text { Mayor vida de anaquel por } 3 \text { semanas más respecto al control } \\
\text { Conservación de los parámetros de calidad (Sólidos solubles } \\
\text { totales, ácido cítrico, vitamina } \mathrm{C} \text {, licopeno) } \\
\text { Conservación de compuestos fenólicos }\end{array}$ & $\begin{array}{l}\text { (Khatri, } \\
\text { Panigrahi, } \\
\text { Prajapati \& } \\
\text { Bariya, 2020) }\end{array}$ \\
\hline $\begin{array}{l}\text { Peso molecular } \\
\text { medio (Grado de } \\
\text { desacetilación } \\
85 \% \text { ) }\end{array}$ & $\begin{array}{c}\text { Quitosano }(0.5,1.0 \\
\text { y } 1.5 \%) \\
\text { Ruta graveolens } \mathrm{L} . \\
(0.5,1.0 \text { y } 1.5 \%)\end{array}$ & $\begin{array}{c}\text { Reducción de la pérdida de peso y la firmeza desde } \\
\text { el día } 3 \text { hasta el día } 12 \text {. } \\
\text { Reducción del deterioro del fruto por la presencia de } \\
\text { microorganismos (bacterias mesófilas aerobias y hongos). } \\
\text { Reducción de la incidencia por enfermedad } \\
\text { hasta en un } 80 \% \text { al día } 12 \text {. }\end{array}$ & $\begin{array}{l}\text { (Peralta-Ruiz } \\
\text { et al., 2020) }\end{array}$ \\
\hline
\end{tabular}

fueron sumergidos durante 5 min en ácido salicílico $1.0 \mathrm{Mm}$ y posteriormente se almacenaron a $4-5{ }^{\circ} \mathrm{C}$. Los resultados muestran que los frutos tratados presentaron una mayor vida de anaquel respecto al control. Además, se observó la conservación de algunos parámetros de calidad como el ácido ascórbico y una menor acumulación de carotenoides y licopeno compuestos relacionados con el proceso de maduración de los frutos (Mandal, Pautu, Hazarika, Nautiyal \& Shukla, 2016). También, se ha reportado que el ácido salicílico $0.75 \mathrm{mM}$ incidió en la reducción de la pérdida de peso, así como, en una menor acumulación de $\beta$-caroteno y licopeno (Kumar, Tokas, Kumar \& Singal, 2018). Por otro lado, el ácido salicílico combinado con timol aplicado en frutos de jitomate muestra un efecto en el control de $R$. stonolifer. Los resultados evidenciaron un daño sobre la estructura de la membrana celular, provocando la fuga de macromoléculas vitales para el crecimiento del patógeno. Así como, el aumento de la actividad enzimática de la polifenol oxidasa (PFO) y PAL, relacionadas con la defensa de los frutos ante la presencia de hongos patógenos (Kong et al., 2019). En el caso del metil jasmonato existen reportes que en concentraciones de 0.01 y $0.05 \mu \mathrm{m}$ sobre jitomates Cherry, estos presentaron un aumento del contendido de ácido ascórbico y carotenoides, especialmente el licopeno. Por lo que, el tratamiento puede beneficiar la maduración de los frutos almacenados hasta por 11 días (Liu et al., 2018b). Además, el metil jasmonato $0.2 \mathrm{mM}$ mostró proteger del daño por frío a los frutos de jitomate cuando estos son almacenados a $2{ }^{\circ} \mathrm{C}$ por 21 días (Zhang, Sheng, Li, Meng \& Shen, 2012). Por lo tanto, el uso de fitohormonas para el control postcosecha de frutos de jitomate puede ser una alternativa al uso de fungicidas sintéticos. Sin embargo, existen pocos estudios sobre el tema, por lo que, se abre una oportunidad para la realización de nuevas investigaciones.

\section{Extractos de plantas}

En la naturaleza, las plantas contienen compuestos bioquímicos que son utilizados selectivamente en el manejo postcosecha de frutos y hortalizas, como una sustitución segura al uso de fungicidas químicos (Chitranshi, Dubey \& Sajjad, 2020). Un 
ejemplo es, (Kator, Oche, Hosea \& Agatsa, 2019) quienes aplicaron un extracto de hojas de moringa a una concentración de $100 \mathrm{~g} / \mathrm{mL}$, sobre frutos de jitomate almacenados 25 días, a temperatura ambiente $(25 \pm 2)$ y humedad relativa del $60-70 \%$. Los resultados mostraron frutos de calidad comercial aceptable y una reducción en el daño ocasionado por patógenos como Aspergillus flavus, Penicillium waksmanii, Botryodiplodia theobromae, Fusarium oxysporum y Colletotrichum asianum, en comparación de aquellos sin tratamiento. En el caso de los extractos de zumaque (Rhus coriaria) aplicados a una concentración de $20 \mu \mathrm{g} / \mathrm{mLen}$ frutos de jitomate; los resultados fueron la inhibición de un $100 \%$ en la incidencia de la infección ocasionada por Colletotrichum acutatum en frutos almacenados durante 10 días a $22{ }^{\circ} \mathrm{C}$ y a una humedad relativa del $53 \%$ (Rashid, Awla \& Sijam, 2018). También, se ha reportado la eficacia de los extractos de pimientos (Capsicum annuиm) en concentraciones de $10 \mathrm{mg} \mathrm{L}^{-1}$ en el control de la pudrición blanda ocasionada por A. alternata hasta en un $57 \%$ con respecto al control (Pane, Fratianni, Parisi, Nazzaro \& Zaccardelli, 2016). Por otro lado, se ha reportado que extractos de las hojas de Flourensia cernua, incorporados a un recubrimiento con base en proteína de suero, glicerol y cera de candelilla forman una barrera protectora, reduciendo la pérdida de peso y firmeza. Además, se observó una mayor vida de anaquel y mejor aspecto visual al final del almacenamiento respecto al control (Ruiz-Martínez et al., 2020). Resultados similares reportaron (Azman, Rostam, Ibrahim \& Lob, 2020) quienes observaron pérdida de peso y firmeza en los frutos de jitomate al día 8 . Después de ser sumergidos de 2-3 min en un tratamiento de extracto de jengibre y almacenados a temperatura ambiente $\left(27^{\circ} \mathrm{C} \pm 2\right)$. En general, la efectividad de los extractos dependerá de los compuestos bioquímicos de la planta, entre ellos los fenólicos (flavonoides), con efecto antifúngico. Por lo tanto, el uso de extractos de plantas, como se mencionó es una opción prometedora al uso de fungicidas químicos, para protección de los frutos al ataque de patógenos durante la etapa postcosecha. Además, son de baja toxicidad y se encuentran en abundancia en la naturaleza (Cortés-Rivera, Blancas-Benitez, Romero-Islas, Gutiérrez-Martinez \& González-Estrada, 2019).

\section{Aceites esenciales}

Los aceites esenciales son compuestos producidos como metabolitos secundarios por las plantas y prácticamente pueden obtenerse de cualquier parte de su estructura: (raíz, corteza, hojas, flores, frutos, cáscaras y exudados). Son conocidos por su amplia utilización en la industria alimentaria y reconocidos como sustancias GRAS. Además, existe un gran interés por sus propiedades antimicrobianas, en la etapa postcosecha de los frutos y las hortalizas (Sivakumar \& Bautista-Baños, 2014; Aguilar-Veloz, Calderón-Santoyo, Vázquez González \& Ragazzo-Sánchez, 2020). Un estudio realizado en los frutos de jitomate, de la variedad Río grande, fueron asperjados con $1 \mathrm{mg} / \mathrm{mL}$ del Ciprés (Cupressus sempervirens). Los resultados evidenciaron una reducción de la infección ocasionada por
B.cinerea en un $54 \%$ (Rguez et al., 2018). También, cuando fue aplicado citral $(1 \mu \mathrm{l} / \mathrm{L})$ y se observó una reducción en la incidencia de la enfermedad del $37.4 \%$ causada por $B$. cinerea, así como, un aumento de la actividad enzimática de la POD y PAL, relacionadas con la defensa de los frutos ante los patógenos (Shenglong et al., 2019). Además, los aceites esenciales como el caso del orégano cuando son incorporados en un recubrimiento a base de alginato de sodio y lecitina pueden reducir el crecimiento total de la carga microbiana, mohos y levaduras en la superficie de los frutos de jitomate Cherry (Pirozzi, Del Grosso, Ferrari \& Donsì, 2020). También los aceites esenciales han sido probados en combinación con otras sustancias antifúngicas como es el caso del timol con ácido salicílico, exhibiendo una sinergia en su efecto preventivo y reduciendo el diámetro de la lesión del fruto, en un 50\% aproximadamente, por hongos como Fusarium solani y $R$. stolonifer. Lo cual es probable gracias a su mecanismo de acción, o sea, la interacción de sus componentes y estructura. En consecuencia, en algunos casos los resultados pueden mostrar diferentes efectos como aditivo, antagonista, sinergia e indiferente (Kong et al., 2016). En general, se ha propuesto también que el mecanismo de acción de los aceites esenciales se debe a su capacidad de penetrar la pared y membranas celulares de los hongos, lo que da lugar a un desequilibrio de los componentes, con pérdida de sus funciones y la salida de compuestos como el adenosín trifosfato (ATP), iones metálicos y aminoácidos necesarios para su desarrollo y crecimiento (Rao, Chen \& McClements, 2019).

\section{Microorganismos}

Actualmente, va en aumento la aplicación del control biológico mediante el uso de microorganismos antagonistas, que producen metabolitos antifúngicos e inhiben el crecimiento de los patógenos, su utilidad es más para la etapa postcosecha que en la precosecha. Los estudios han ampliado el conocimiento sobre otros mecanismos de acción con actividad antifúngica, como la competencia de nutrientes y espacio, también la secreción de antibióticos antifúngicos, mico-parasitismo e inducción de resistencia (Carmona-Hernandez et al., 2019; Dukare et al., 2019). En la década pasada, se reportó un estudio con la levadura marina Rhodosporidium paludigenum, los resultados evidenciaron una reducción de la incidencia de la enfermedad por hongos en aproximadamente un $36 \%$ en los frutos de jitomate Cherry inoculados con $B$. cinerea y almacenados a $25^{\circ} \mathrm{C}$ durante 5 días (Wang et al., 2010). También, la quitina aislada de la levadura Saccharomyces cerevisiae mostró un efecto inhibidor sobre el moho gris causado por $B$. cinerea entre 12 y 24 horas. Esto sugiere que su actividad antifúngica podría estar relacionada con el aumento de las enzimas: superóxido dismutasa (SOD), catalasa (CAT), POD, PAL, GLU y QUI, relacionadas con la defensa de los frutos, y un pico de acción más alto entre las 12 y 24 horas (Sun et al., 2018). En el caso de Cryptococcus laurentii, aplicado en frutos de jitomate Cherry, los resultados evidenciaron una reducción de la incidencia de la enfermedad ocasionada por B. cinerea y A. alternata, en un 59.5 y $59.1 \%$ 
respectivamente, menos que el control a las 48 horas después de la inoculación. Probablemente también por la inducción de las enzimas: CAT, SOD, POD, PAL, GLU y QUI y su resistencia a los patógenos (Lai et al., 2018). De igual manera, C. laurentii aplicada en los frutos de jitomate Cherry, se observó una reducción del $28.3 \%$ en la incidencia de la enfermedad por $B$. cinerea respecto al control a las 60 horas después de la inoculación. Además, de la acumulación del etileno, reportado por su relación con las vías de señalización relacionadas a la capacidad de defensa de los frutos climatéricos (Tang et al., 2019). Sin embargo, el uso de microorganismos para el control de los patógenos todavía es limitado. Por lo que, es necesario combinarlos con otros métodos físicos o químicos que brinden mayor efectividad y apoyados con estudios que involucren la participación de organizaciones académicas, iniciativas privadas y gubernamentales (Abbey et al., 2019). Además de ser una oportunidad para investigar el uso de microorganismos como control biológico postcosecha en los frutos de jitomate.

\section{Conclusiones}

El jitomate se encuentra dentro de los 10 cultivos con mayor valor comercial. Sin embargo, también es uno de los frutos más perecederos, que puede ser afectado por factores bióticos y abióticos, durante su manejo postcosecha. A la fecha, el uso de fungicidas sintéticos como estrategia ha presentado resultados satisfactorios para el control de las enfermedades postcosecha en los frutos de jitomate, sin embargo, en los últimos años existe una tendencia, de parte de la sociedad y de los consumidores de un rechazo al uso de plaguicidas y demandan productos libres de esos residuos. Acorde con lo hasta aquí mencionado y con los informes presentados, existen sistemas de control eficaces y prometedores para el manejo postcosecha de los frutos de jitomate; protegiéndolos del ataque de patógenos, conservando su calidad nutracéutica y atributos sensoriales. Sin embargo, insistimos en que se requieren de más estudios in vivo que puedan ser implementados no sólo en la etapa postcosecha sino también a nivel de precosecha.

\section{Agradecimientos}

Se agradece el apoyo al CONACYT por la beca de doctorado otorgada al M.C.A. Carlos Azhael Rodríguez Guzmán y al Laboratorio Integral de Investigación en Alimentos (LIIA) del Instituto Tecnológico de Tepic.

\section{REFERENCIAS}

Abbey, J. A., Percival, D., Abbey, L., Asiedu, S. K., Prithiviraj, B. \& Schilder, A. (2019). Biofungicides as alternative to synthetic fungicide control of grey mould (Botrytis cinerea) - prospects and challenges. Biocontrol Science and Technology, 29(3), 207-228. https://doi.org/10.1080/ 09583157.2018.1548574

Abdel-Rahman, F. A., Rashid, I. A. \& Shoala, T. (2020). Nanoactivities of natural nanomaterials rosmarinic acid, glycyrrhizic acid and glycyrrhizic acid ammonium salt against tomato phytopathogenic fungi Alternaria alternata and Penicillium digitatum. Journal of Plant Protection Research, 60(2), 150-160. https://doi.org/10.24425/ jppr.2020.133309

Abu-El Samen, F., Goussous, S. J., Al-Shudifat, A. \& Makhadmeh, I. (2016). Reduced sensitivity of tomato early blight pathogen (Alternaria solani) isolates to protectant fungicides, and implication on disease control. Archives of Phytopathology and Plant Protection, 49(5-6), 120-136. https://doi.org/10.1080/03235408.2016.1160641

Aguilar-Veloz, L. M., Calderón-Santoyo, M., Vázquez González, Y. \& Ragazzo-Sánchez, J. A. (2020). Application of essential oils and polyphenols as natural antimicrobial agents in postharvest treatments: Advances and challenges. Food Science \& Nutrition, 8(6), 2555-2568. https://doi. org/10.1002/fsn3.1437

Alaoui, F.T, Askarne, L., Boubaker, H., Boudyach, E. \& Aomar, A. B. (2017). Control of gray mold disease of tomato by post-harvest application of organic acids and salts. Plant Pathology Journal, 16(2), 62-72. https://doi.org/10.3923/ ppj.2017.62.72

Alfaro-Sifuentes, L., Juan, M., Troncoso-Rojas, R., Meca, D. E., Elorrieta, M. A. \& Valenzuela, J. L. (2019). Effectiveness of chemical and thermal treatments on control Rhizopus stolonifer fruit infection comparing tomato cultivars with different sensitivities to cracking. International Journal of Environmental Research and Public Health, 16(15), 2754. https://doi.org/10.3390/ijerph16152754

Arah, I. K., Ahorbo, G. K., Anku, E. K., Kumah, E. K. \&Amaglo, H. (2016). Post-harvest handling practices and treatment methods for tomato handlers in developing countries: A mini review. Advances in Agriculture, 2016,1-8. https:// doi.org/10.1155/2016/6436945

Arah, I. K., Amaglo, H., Kumah, E. K. \& Ofori, H. (2015). Preharvest and post-harvest factors affecting the quality and shelf life of harvested tomatoes: A mini review. International Journal of Agronomy, (2015) 1-6. https:// doi.org/10.1155/2015/478041

Athayde, A. J. A. A., De Oliveira, P. D. L., Guerra, I. C. D., Da Conceição, M. L., De Lima, M. A. B., Arcanjo, N. M. O., Madruga, M. S., Berger, L. R. R. \& de Souza, E. L. (2016). A coating composed of chitosan and Cymbopogon citratus (Dc. Ex Nees) essential oil to control Rhizopus soft rot and quality in tomato fruit stored at room temperature. The Journal of Horticultural Science and Biotechnology, 91(6), 582-591. https://doi.org/10.1080/14620316.2016 .1193428

Azman, N. A. I. N., Rostam, N. F. S., Ibrahim, N. F. \& Lob, S. (2020). Potential of aqueous ginger extract as fruit coating on tomato. Universiti Malaysia Terengganu Journal of Undergraduate Research, 2(4), 23-30.

Bautista-Baños, S., Ventura-Aguilar, R. I., Correa-Pacheco, Z. \& Corona-Rangel, M. L. (2017). Chitosan: a versatile antimicrobial polysaccharide for fruit and vegetables 
in post-harvest - a review. Revista Chapingo Serie Horticultura, 23(2), 103-121. http://dx.doi.org/10.5154/r. rchsh.2016.11.030

Boonkorn, P. (2016). Impact of hot water soaking on antioxidant enzyme activities and some qualities of storage tomato fruits. International Food Research Journal, 23(3), 934-938.

$\mathrm{Bu}$, J., Yu, Y., Aisikaer, G. \& Ying, T. (2013). Postharvest UV-C irradiation inhibits the production of ethylene and the activity of cell wall-degrading enzymes during softening of tomato (Lycopersicon esculentum L.) fruit. Postharvest Biology and Technology, 86, 337-345. https:// doi.org/10.1016/j.postharvbio.2013.07.026

Carmona-Hernandez, S., Reyes-Pérez, J. J., ChiquitoContreras, R. G., Rincon-Enriquez, G., Cerdan-Cabrera, C. R. \& Hernandez-Montiel, L. G. (2019). Biocontrol of postharvest fruit fungal diseases by bacterial antagonists: A review. Agronomy, 9(3), 121. https://doi.org/10.3390/ agronomy9030121

Carvalho, F. P. (2006). Agriculture, pesticides, food security and food safety. Environmental Science and Policy, 9(7-8), 685-692. https://doi.org/10.1016/j.envsci.2006.08.002

Chapin, L. J. G., Wang, Y., Lutton, E. \& Gardener, B. B. M. (2006). Distribution and fungicide sensitivity of fungal pathogens causing anthracnose-like lesions on tomatoes grown in Ohio. Plant Disease, 90(4), 397-403. https://doi. org/10.1094/pd-90-0397

Charles, M. T., Arul, J., Charlebois, D., Yaganza, E. S., Rolland, D., Roussel, D. \& Merisier, M. J. (2016). Postharvest UV-C treatment of tomato fruits: Changes in simple sugars and organic acids contents during storage. LWT - Food Science and Technology, 65, 557-564. DOI: https://doi. org/10.1016/j.lwt.2015.08.055

Chitranshi, S., Dubey, N. \& Sajjad, M. (2020). Sustainable botanical products for safe post-harvest management of perishable produce: A review. Journal of Horticulture and Postharvest Research 3(1), 125-140. https://doi. org/10.22077/JHPR.2019.2703.1083

Chudinova, E. M., Shkunkova, T. A. \& Elansky, S. N. (2020). Fungal pathogens of tomato in South-Western Russia (Krasnodar Territory). Plant Protection News, (3), 210-212. https://doi.org/10.31993/2308-6459-2020-103-3-4998

Cortés-Rivera, H. J., Blancas-Benitez, F. J., Romero-Islas, L. C., Gutiérrez-Martinez, P. \& González-Estrada, R. R. (2019). In vitro evaluation of residues of coconut (Cocos nucifera $\mathrm{L}$.) aqueous extracts, against the fungus Penicillium italicum. Emirates Journal of Food and Agriculture, 31(8), 613-617. https://doi.org/10.9755/ejfa.2019.v31.i8.1993

Duan, C., Meng, X., Meng, J., Khan, M.I.H., Dai, L., Khan, A., An, X., Zhang J., Huq, T. \& Ni, Y. (2019). Chitosan as a preservative for fruits and vegetables: A review on chemistry and antimicrobial properties. Journal of Bioresources and Bioproducts, 4(1), 11-21. https://doi. org/10.21967/jbb.v4i1.189

Dukare, A. S., Paul, S., Nambi, V. E., Gupta, R. K., Singh, R.,
Sharma, K. \& Vishwakarma, R. K. (2019). Exploitation of microbial antagonists for the control of post-harvest diseases of fruits: a review. Critical Reviews in Food Science and Nutrition, 59(9), 1498-1513. https://doi.org/10.1080/104 08398.2017 .1417235

Dyshlyuk, L., Babich, O., Prosekov, A., Ivanova, S., Pavsky, V. \& Chaplygina, T. (2020). The effect of post-harvest ultraviolet irradiation on the content of antioxidant compounds and the activity of antioxidant enzymes in tomato. Heliyon, 6(1), https://doi.org/10.1016/j.heliyon.2020.e03288

e-CFR. Electronic Code of Federal Regulations (2020). https:// www.ecfr.gov/cgi-bin/text-idx?SID $=186 \mathrm{c} 36 \mathrm{f} 172 \mathrm{c} 2 \mathrm{a} 5 \mathrm{f}$ 98f740677f73ae152\&node $=40: 24.0 .1 .1 .27 \&$ rgn $=\operatorname{div} 5 \#$ se40.26.180 131 Fecha de acceso: 05/02/2020.

Esua, O. J., Chin, N. L., Yusof, Y.A. \& Sukor, R. (2019). Effects of simultaneous UV-C radiation and ultrasonic energy postharvest treatment on bioactive compounds and antioxidant activity of tomatoes during storage. Food Chemistry, 270, 113-122.https://doi.org/10.1016/j.foodchem.2018.07.031

EU legislation on MRLs. European Commission (2020). http:// ec.europa.eu/food/plant/ Fecha de acceso: 6/02/2020.

Fagundes, C., Palou, L., Monteiro, A. R. \& Pérez-Gago, M. B. (2014). Effect of antifungal hydroxypropyl methylcellulosebeeswax edible coatings on gray mold development and quality attributes of cold-stored cherry tomato fruit. Postharvest Biology and Technology, 92, 1-8. https://doi. org/10.1016/j.postharvbio.2014.01.006

Fagundes, C., Palou, L., Monteiro, A. R. \& Pérez-Gago, M. B. (2015). Hydroxypropyl methylcellulose-beeswax edible coatings formulated with antifungal food additives to reduce alternaria black spot and maintain post-harvest quality of cold-stored cherry tomatoes. Scientia Horticulturae, 193, 249-257. https://doi.org/10.1016/j.scienta.2015.07.027

FAOSTAT. United Nations Food and Agriculture Organization (2019). Food and agriculture data. http://www.fao.org/ faostat/en/\#data/QC Fecha de acceso: 9/10/2019

FRAC. Fungicide Resistance Action Commitee. (2020).

http://www.frac.info/publications/downloads Fecha de acceso: $2 / 02 / 2020$.

Ghazanfar, M. U., Raza, W., Ahmed, K. S., Qamar, J., Haider, N. \& Rasheed,M.H.(2016). Evaluation of different fungicides against Alternaria solani (Ellis \& Martin) Sorauer cause of early blight of tomato under laboratory conditions. International Journal of Zoology Studies, 1(5). 08-12

González-Estrada, R .R., Blancas-Benítez, F., VelázquezEstrada, R. M., Montaño-Leyva, B., Ramos-Guerrero, A., Aguirre-Güitrón, L., Moreno-Hernández, C., CoronadoPartida, L. D., Herrera-González, J.A., Rodríguez-Guzmán, C.A., Del Ángel-Cruz, J.A., Rayón-Díaz, E., Cortés-Rivera, H. J., Santoyo-González, M. A. \& Gutiérrez-Martínez, P. (2019). Alternative eco-friendly methods in the control of post-harvest decay of tropical and subtropical fruits. In: Modern Fruit Industry. IntechOpen. (1), 3-24 https://doi. org/10.5772/intechopen.85682 
Guo, H., Qiao, B., Ji, X., Wang, X. \& Zhu, E. (2020). Antifungal activity and possible mechanisms of submicron chitosan dispersions against Alteraria alternata. Postharvest Biology and Technology, 161, 110883. https://doi.org/10.1016/j. postharvbio.2019.04.009

Gutiérrez-Martínez, P., Ramos-Guerrero,A., Rodríguez-Pereida, C., Coronado-Partida, L., Angulo-Parra, J. \& GonzálezEstrada, R. (2018). Chitosan for postharvest disinfection of fruits and vegetables. Postharvest Disinfection of Fruits and Vegetables, 1(12), 231-241. https://doi.org/10.1016/ B978-0-12-812698-1.00012-1

Habib, W., Saab, C., Malek, R., Kattoura, L., Rotolo, C., Gerges, E., Baroudy, F., Pollastro, S., Faretra, F. \& De Miccolis Angelini, R.M.(2020). Resistance profiles of Botrytis cinerea populations to several fungicide classes on greenhouse tomato and strawberry in Lebanon. Plant Pathology, 69(8), 1453-1468. https://doi.org/10.1111/ppa.13228

Imahori, Y., Bai, J. \& Baldwin, E. (2016). Antioxidative responses of ripe tomato fruit to post-harvest chilling and heating treatments. Scientia Horticulturae, 198, 398-406. https://doi.org/10.1016/j.scienta.2015.12.006

Jabnoun-Khiareddine, H., Abdallah, R., El-Mohamedy, R., Abdel-Kareem, F., Gueddes-Chahed, M., Hajlaoiui, A. \& Daami-Remadi, M. (2016). Comparative efficacy of potassium salts against soil-borne and air-borne fungi and their ability to suppress tomato wilt and fruit rots. Journal of Microbial \& Biochemical Technology, 8(2), 45-55. https:// doi.org/10.4172/1948-5948.1000261

Jiang, N., Li, Z., Wang, L., Li, H., Zhu, X., Feng, X. \& Wang, M. (2019). Effects of ultraviolet-c treatment on growth and mycotoxin production by Alternaria strains isolated from tomato fruits. International Journal of Food Microbiology, 311, 108333 https://doi.org/10.1016/j. ijfoodmicro.2019.108333

Kator, L., Oche, O. D., Hosea, Z. Y. \& Agatsa, T. D. (2019). Effect of aqueous extract of moringa leaves on post-harvest shelf life and quality of tomato fruits inoculated with fungal pathogens in Makurdi. Asian Journal of Agricultural and Horticultural Research,3(1), 1-13.https://doi.org/10.9734/ ajahr/2019/45766

Khatri, D., Panigrahi, J., Prajapati, A. \& Bariya, H. (2020). Attributes of Aloe vera gel and chitosan treatments on the quality and biochemical traits of post-harvest tomatoes. Scientia Horticulturae, 259, 108837 https://doi. org/10.1016/j.scienta.2019.108837

Khubone, L. W. \& Mditshwa, A. (2018). The effects of UV-C irradiation on post-harvest quality of tomatoes (Solanum lycopersicum). Acta Horticulturae, 1201, 75-82. https:// doi.org/10.17660/ActaHortic.2018.1201.11

Kibar, H. F. \& K. Sabir, F. K. (2018). Chitosan coating for extending post-harvest quality of tomatoes (Lycopersicon esculentum Mill.) maintained at different storage. AIMS Agriculture and Food, 3(2), 97-108. https://doi. org/10.3934/agrfood.2018.2.97
Kim, K. H., Kabir, E. \& Jahan, S. A. (2017). Exposure to pesticides and the associated human health effects. Science of the total environment, 575, 525-535. https:// doi.org/10.1016/j.scitotenv.2016.09.009

Kong, J., Zhang, Y., Ju, J., Xie, Y., Guo, Y., Cheng, Y., Qian, H., Quek, S. Y. \& Yao, W. (2019). Antifungal effects of thymol and salicylic acid on cell membrane and mitochondria of Rhizopus stolonifer and their application in post-harvest preservation of tomatoes. Food Chemistry, 285, 380-388. https://doi.org/10.1016/j.foodchem.2019.01.099

Kumar, N., Tokas, J., Kumar, P. \& Singal, H. R. (2018). Effect of salicylic acid on post-harvest quality of tomato (Solanum lycopersicum L .) Fruit. 6(1), 1744-1747.

Lai, J., Cao, X., Yu, T., Wang, Q., Zhang, Y., Zheng, X. \& Lu, H. (2018). Effect of Cryptococcus laurentii on inducing disease resistance in cherry tomato fruit with focus on the expression of defense-related genes. Food Chemistry, 254, 208-216.https://doi.org/10.1016/j.foodchem.2018.01.100

Liu, C., Zheng, H., Sheng, K., Liu, W. \& Zheng, L. (2018a). Effects of post-harvest UV-C irradiation on phenolic acids, flavonoids, and key phenylpropanoid pathway genes in tomato fruit. Scientia Horticulturae, 241, 107-114. https:// doi.org/10.1016/j.scienta.2018.06.075

Liu, H., Meng, F., Miao, H., Chen, S., Yin, T., Hu, S., Shao, Z., Liu, Y., Gao, L., Zhu, C., Zhang, B. \& Wang, Q. (2018b). Effects of post-harvest methyl jasmonate treatment on main health-promoting components and volatile organic compounds in cherry tomato fruits. Food Chemistry, 263, 194-200.https://doi.org/10.1016/j.foodchem.2018.04.124

Liu, S., Fu, L., Tan, H., Jiang, J., Che, Z., Tian, Y. \& Chen, G. (2021). Resistance to boscalid in Botrytis cinerea from greenhouse grown tomato. Plant Disease, 105(3) 628-635 https://doi.org/10.1094/PDIS-06-20-1191-RE

Loayza, F. E., Brecht, J. K., Simonne, A. H., Plotto, A., Baldwin, E. A., Bai, J. \& Lon-kan, E. (2020). A brief hot-water treatment alleviates chilling injury symptoms in fresh tomatoes. Journal of the Science of Food and Agriculture, 101(1), 54-64 https://doi.org/10.1002/jsfa.10821

Lu, H., Li, L., Limwachiranon, J., Xie, J. \& Luo, Z. (2016). Effect of UV-C on ripening of tomato fruits in response to wound. Scientia Horticulturae, 213, 104-109. https://doi. org/10.1016/j.scienta.2016.10.017

Mandal, D., Pautu, L., Hazarika, T. K., Nautiyal, B. P. \& Shukla, A. C. (2016). Effect of salicylic acid on physico-chemical attributes and shelf life of tomato fruits at refrigerated storage effect of salicylic acid on physico-chemical attributes and shelf life of tomato fruits at refrigerated storage. International Journal of Bio-resource and Stress Management, 7(6), 1272-1278. https://doi.org//10.23910/ IJBSM/2016.7.6.1683b

Mandal, D. \& Shukla, A. C. (2018). Effect of chitosan, wax and particle film coating on shelf life and quality of tomato cv. Samrudhi at ambient storage. Research Journal of Agricultural Sciences, 9, 111-116. 
Manigandan, V., Karthik, R., Ramachandran, S. \& Rajagopal, S. (2018). Chitosan applications in food industry. In Biopolymers for Food Design. 20(15) 469-491. Elsevier. https://doi.org/10.1016/B978-0-12-811449-0.00015-3

Mansourbahmani, S., Ghareyazie, B., Kalatejari, S., Mohammadi, R. S. \& Zarinnia, V. (2017). Effect of post-harvest UV-C irradiation and calcium chloride on enzymatic activity and decay of tomato (Lycopersicon esculentum L.) fruit during storage. Journal of Integrative Agriculture, 16(9), 2093-2100. https://doi.org/10.1016/ S2095-3119(16)61569-1

Martínez-Ruiz, F. E., Cervantes-Díaz, L., Aíl-Catzím, C. E., Hernández-Montiel, L. G., Sánchez, C. L. D. T. \& RuedaPuente, E. O. (2016). Hongos fitopatógenos asociados al tomate (Solanum lycopersicum 1.) en la zona árida del noroeste de México: la importancia de su diagnóstico. European Scientific Journal, 12(18), 232. https://doi. org/10.19044/esj.2016.v12n18p232

Matyjaszczyk, E. (2015). Prevention methods for pest control and their use in Poland. Pest management science, 71(4), 485-491.

Mditshwa, A., Magwaza, L. S., Tesfay, S. Z. \& Mbili, N. C. (2017). Effect of ultraviolet irradiation on post-harvest quality and composition of tomatoes: a review. Journal of Food Science and Technology, 54(10), 3025-3035. https:// doi.org/10.1007/s13197-017-2802-6

Olaiya, C. O., Karigidi, K. O., Ogunleye, A. B. \& Kareem, O. R. (2016). Possible enhancement of nutrients and antioxidant capacity of two tropical fruits by UV radiation treatment. Advances in Life Science and Technology. 46, 80-85

Pagno, C. H., Castagna, A., Trivellini, A., Mensuali-Sodi, A., Ranieri, A., Ferreira, E. A., Rios, A. de O. \& Flôres, S. H. (2018). The nutraceutical quality of tomato fruit during domestic storage is affected by chitosan coating. Journal of Food Processing and Preservation, 42(1), e13326. https:// doi.org/10.1111/jfpp.13326

Palou, L., Ali, A., Fallik, E. \& Romanazzi, G. (2016). GRAS, plant- and animal-derived compounds as alternatives to conventional fungicides for the control of post-harvest diseases of fresh horticultural produce. Postharvest Biology and Technology, 122, 41-52. https://doi.org/10.1016/j. postharvbio.2016.04.017

Pane, C., Fratianni, F., Parisi, M., Nazzaro, F. \& Zaccardelli, M. (2016). Control of Alternaria post-harvest infections on cherry tomato fruits by wild pepper phenolic-rich extracts. Crop Protection, 84, 81-87. https://doi.org/10.1016/j. cropro.2016.02.015

Parvin, N., Kader, M. A., Huque, R., Molla, M. E. \& Khan, M. A. (2018). Extension of shelf-life of tomato using irradiated chitosan and its physical and biochemical characteristics. InternationalLetters of Natural Sciences, 67, 16-23. https:// doi.org/10.18052/www.scipress.com/ILNS.67.16

Pataro, G., Sinik, M., Capitoli, M. M., Donsì, G. \& Ferrari, G. (2015). The influence of post-harvest UV-C and pulsed light treatments on quality and antioxidant properties of tomato fruits during storage. Innovative Food Science \& Emerging Technologies, 30, 103-111. https://doi.org/10.1016/j. ifset.2015.06.003

Patel, N. A., Dange, S. R. S. \& Patel, S. I. (2005). Efficacy of chemicals in controlling fruit rot of tomato caused by Alternaria tomato. Indian Journal of Agricultural Research, 39(1), 72-75.

Peralta-Ruiz, Y., Tovar, C. D. G., Sinning-Mangonez, A., Coronell, E. A., Marino, M. F. \& Chaves-Lopez, C. (2020). Reduction of post-harvest quality loss and microbiological decay of tomato "chonto" (Solanum lycopersicum L.) using chitosan-e essential oil-based edible coatings under low-temperature storage. Polymers, 12(8), 1822. https:// doi.org/10.3390/polym12081822

Pinheiro, J., Alegria, C., Abreu, M., Gonçalves, E. M. \& Silva, C. L. M. (2015). Use of UV-C post-harvest treatment for extending fresh whole tomato (Solanum lycopersicum, cv. Zinac) shelf-life. Journal of Food Science and Technology, 52(8), 5066-5074. https://doi.org/10.1007/s13197-014$1550-0$

Pinheiro, J., Ganhao, R., Goncalves E. M. \& Silva, C. L. M. (2019). Assessment of thermosonication as post-harvest treatment applied on whole tomato fruits: Optimization and validation. Foods 8(12) 649. https://doi.org/10.3390/ foods 8120649

Pirozzi,A., Del Grosso, V., Ferrari, G. \& Donsì, F. (2020). Edible coatings containing oregano essential oil nanoemulsion for improving post-harvest quality and shelf life of tomatoes. Foods, 9(11), 1605.https://doi.org/10.3390/foods9111605

Poveda, J. (2020). Use of plant-defense hormones against pathogen-diseases of post-harvest fresh produce. Physiological and Molecular Plant Pathology, 111, 101521. https://doi.org/10.1016/j.pmpp.2020.101521

Rani, S., Singh, R. \& Gupta, S. (2017). Development of integrated disease management module for early blight of tomato in Jammu. Journal of Pharmacognosy and Phytochemistry, 6(2), 268-273.

Rao, J., Chen, B. \& McClements, D. J. (2019). Improving the efficacy of essential oils as antimicrobials in foods: mechanisms of action. Annual Review of Food Science and Technology, 10(1), 365-387. https://doi.org/10.1146/ annurev-food-032818-121727

Rashid, T. S., Awla, H. K.\& Sijam, K. (2018). Antifungal effects of Rhus coriaria $\mathrm{L}$. fruit extracts against tomato anthracnose caused by Colletotrichum acutatum. Industrial Crops and Products, 113, 391-397. https://doi.org/10.1016/j. indcrop.2018.01.066

Rguez, S., Djébali, N., Slimene, I. B., Abid, G., Hammemi, M., Chenenaoui, S., Bachkouel, S., Daami-Remadi, M., Ksouri, R. \& Hamrouni-Sellami, I. (2018). Cupressus sempervirens essential oils and their major compounds successfully control post-harvest grey mould disease of tomato. Industrial Crops and Products, 123, 135-141. 
https://doi.org/10.1016/j.indcrop.2018.06.060

Rives-Castillo, S. C. H., Ventura-Aguilar, R. I., HernándezLópez, M. \& Bautista-Baños, S. (2018). Extensión de la vida de anaquel y conservación postcosecha de jitomates var. 'Kenton' mediante la aplicación de recubrimientos biodegradables. Acta Agricola y Pecuaria, 4(3), 80-91. https://dialnet.unirioja.es/servlet/articulo?codigo $=6788414$

Rodrigues, B. B. \& Kakde, U. B. (2019). Post harvest fungi associated with Solanum lycopersicum (Tomato) fruits collected from different markets of Mumbai. International Interdisciplinary Research Journa, 9(1). 52-60.

Rodríguez-Guzmán, C. A., González-Estrada, R. R., BautistaBaños, S. \& Gutiérrez-Martínez, P. (2019). Efecto del quitosano en el control de Alternaria sp. en plantas de jitomate en invernadero. TIP Revista Especializada en Ciencias Químico-Biológicas, 22, 1-7. https://doi. org/10.22201/fesz.23958723e.2019.0.161

Romanazzi, G., Feliziani, E., Baños, S. B. \& Sivakumar, D. (2017). Shelf life extension of fresh fruit and vegetables by chitosan treatment. Critical Reviews in Food Science and Nutrition, 57(3), 579-601. https://doi.org/10.1080/10 408398.2014.900474

Romanazzi, G., Feliziani, E. \& Sivakumar, D. (2018). Chitosan, a biopolymer with triple action on post-harvest decay of fruit and vegetables: Eliciting, antimicrobial and film-forming properties. Frontiers in Microbiology, 9, 1-9. https://doi. org/10.3389/fmicb.2018.02745

Romanazzi, G., Sanzani, S. M., Bi, Y., Tian, S., GutiérrezMartínez, P. \& Alkan, N. (2016a). Induced resistance to control postharvest decay of fruit and vegetables. Postharvest Biology and Technology, 122, 82-94. https:// doi.org/10.1016/j.postharvbio.2016.08.003

Romanazzi, G., Smilanick, J. L., Feliziani, E. \& Droby, S. (2016b). Integrated management of post-harvest gray mold on fruit crops. Postharvest Biology and Technology, 113, 69-76. https://doi.org/10.1016/j.postharvbio.2015.11.003

Ruiz-Martínez, J., Aguirre-Joya, J. A., Rojas, R., Vicente, A., Aguilar-González, M. A., Rodríguez-Herrera, R., AlvarezPerez, O. B., Torres-León, C. \& Aguilar, C. N. (2020). Candelilla wax edible coating with Flourensia cernua bioactives to prolong the quality of tomato fruits. Foods, 9(9), 1303. https://doi.org/10.3390/foods9091303

Sajad,A. M. \& Jamaluddin Abid, H. Q. (2017). Fungi associated with the spoilage of post harvest tomato fruits and their frequency of occurences in different markets of jabalpur, Madhya-Pradesh, India. Int J. Cur. Res, Rev., 9(5), 12-16.

Salas-Méndez, E. de J., Vicente, A., Pinheiro, A. C., Ballesteros, L. F., Silva, P., Rodríguez-García, R., Hernández-Castillo, F. D., Díaz-Jiménez, M. de L. V., Flores-López, M. L., Villarreal-Quintanilla, J. Á., Peña-Ramos, F. M., CarrilloLomelí, D.A. \& Jasso de Rodríguez, D. (2019). Application of edible nanolaminate coatings with antimicrobial extract of Flourensia cernua to extend the shelf-life of tomato (Solanum lycopersicum L.) fruit. Postharvest Biology and Technology, 150, 19-27. https://doi.org/10.1016/j. postharvbio.2018.12.008

Shama, G. \& Alderson, P. (2005). UV hormesis in fruits: A concept ripe for commercialisation. Trends in Food Science and Technology, 16(4), 128-136. https://doi.org/10.1016/j. tifs.2004.10.001

Shamurailatpam, D. \& Kumar A. (2020). A review on recent methods to control early blight of tomato (Solanum lycopersicum L.). Plant Cell Biotechnology and Molecular Biology, 21, 136-148.

Sharif, M. A., Kumer, A., Ahmed, M. B. \& Paul, S. (2018). Chitosan is a new target of chemical replacement to formalin in food preservative. International Journal of Chemical Studies, 6(1), 757-760.

Shenglong, D., Jihong, Z., Shaoyang, C., Shuang, M. \& Li, Z. (2019). The combined effect of 1-methylcyclopropene and citral suppressed post-harvest grey mould of tomato fruit by inhibiting the growth of Botrytis cinerea. Journal of Phytopathology, 167(2), 123-134.https://doi.org/10.1111/ jph.12780

Shridhar, B. P., Sharma, M., Gupta, S. K. \& Sharma, S. K. (2018). New generation fungicides for the management of buckeye rot of tomato. Indian Phytopathology, 71(4), 621-625. https://doi.org/10.1007/s42360-018-0079-y

SIAP. Servicio de Información Agroalimentaria y Pesquera. (2019). Atlas agroalimentario 2018. https://www.gob.mx/ siap/acciones-y-programas/atlas-agroalimentario-2018 Fecha de acceso: 06/10/2019.

Singh, J., Roy, B., Mishra, S. \& Garg, R. (2020). Post-harvest treatment for preserving antioxidant properties and total phenolic content of tomatoes and litchis. Journal of Thematic Analysis, 1(1), 125-135.

Sivakumar, D. \& Bautista-Baños, S. (2014). A review on the use of essential oils for post-harvest decay control and maintenance of fruit quality during storage. Crop Protection, 64, 27-37. https://doi.org/10.1016/j.cropro.2014.05.012

Sivakumar, D. \& Fallik, E. (2013). Influence of heat treatments on quality retention of fresh and fresh-cut produce. Food Reviews International, 29(3), 294-320. https://doi.org/10 .1080/87559129.2013.790048

Sree, K. P., Sree, M. S. \& Samreen, P. S. (2020). Application of chitosan edible coating for preservation of tomato. International Journal of Chemical Studies, 8(4), 3281-3285. https://doi.org/10.22271/chemi.2020.v8.i4ao.10157

Sucharitha, K. V., Beulah, A. M. \& Ravikiran, K. (2018). Effect of chitosan coating on storage stability of tomatoes (Lycopersicon esculentum Mill). In International Food Research Journal, 25(1), 93-99.

Sultana, N., Zakir, H. M., Parvin, M. A., Sharmin, S. \& Seal, H. P. (2019). Effect of chitosan coating on physiological responses and nutritional qualities of tomato fruits during post-harvest storage. Asian Journal of Advances in Agricultural Research,10(2), 1-11.https://doi.org/10.9734/ ajaar/2019/v10i230027 
Sun, C., Fu, D., Jin, L., Chen, M., Zheng, X. \& Yu, T. (2018). Chitin isolated from yeast cell wall induces the resistance of tomato fruit to Botrytis cinerea. Carbohydrate Polymers, 199, 341-352. https://doi.org/10.1016/j. carbpol.2018.07.045

Tadesse, T. N. \& Abtew, W. G. (2016). Effect of hot water treatment on reduction of chilling injury and keeping quality in tomato (Solanum lycopersicum L.) fruits. Journal of Stored Products and Postharvest Research, 7(7), 61-68. https://academicjournals.org/journal/JSPPR/ article-abstract/985D59660444

Tang, Q., Zhu, F., Cao, X., Zheng, X., Yu, T. \& Lu, L. (2019). Cryptococcus laurentii controls gray mold of cherry tomato fruit via modulation of ethylene-associated immune responses. Food Chemistry, 278, 240-247. https://doi. org/10.1016/j.foodchem.2018.11.051

Tauxe, R. V. (2001). Food safety and irradiation: protecting the public from foodborne infections. Emerging Infectious Diseases, 7(7), 516-521. https://doi.org/10.3201/ eid0707.017706

The Japan Food Chemical Research Foundation. (2020). Search engine for MRLs. http://db.ffcr.or.jp/front/food_group_ comp Fecha de acceso: 8/02/2020.

Venditti, T., D'hallewin, G., Ladu, G., Petretto, G. L., Pintore, G. \& Labavitch, J. M. (2018). Effect of $\mathrm{NaHCO}_{3}$ treatments on the activity of cell-wall-degrading enzymes produced by Penicillium digitatum during the pathogenesis process on grapefruit. Journal of the Science of Food and Agriculture, 98(13), 4928-4936. https://doi.org/10.1002/jsfa.9025

Vincent, H., Wiersema, J., Kell, S., Fielder, H., Dobbie, S., Castañeda-Álvarez, N.P., Guarino, L., Eastwood, R., León, B. \& Maxted, N. (2013). A prioritized crop wild relative inventory to help underpin global food security. Biological Conservation, 167, 265-275. https://doi.org/10.1016/j. biocon.2013.08.011

Wanasinghe, W. U. T. \& Damunupola, J. W. (2020). Effect of UV-C hormesis in regulating anthracnose disease and post-harvest quality of tomato. Journal of Agricultural Sciences - Sri Lanka, 15(3), 318. https://doi.org/10.4038/ jas.v15i3.9024

Wang, L., Baldwin, E., Luo, W., Zhao, W., Brecht, J. \& Bai, J. (2019a) Key tomato volatile compounds during postharvest ripening in response to chilling and pre-chilling heat treatments. Postharvest Biology and Technology, 154, 11-20. https://doi.org/10.1016/j.postharvbio.2019.04.013

Wang, X. M., Du, X.F., Nong, Y.U.A.N. \& Shao, H. (2019b). Growth-inhibition of 12 fungicides against Botrytis cinerea in tomato and their preventive effects in field. Pakistan Journal of Botany, 51(6), 2291-2294. https://doi. org/10.30848/PJB2019-6(32)

Wang, Y., Yu, T., Xia, J., Yu, D., Wang, J. \& Zheng, X. (2010). Biocontrol of post-harvest gray mold of cherry tomatoes with the marine yeast Rhodosporidium paludigenum. Biological Control, 53(2), 178-182. https://doi.org/10.1016/j. biocontrol.2010.01.002

Wei, Y., Xu, M., Wu, H., Tu, S., Pan, L. \& Tu, K. (2016). Defense response of cherry tomato at different maturity stages to combined treatment of hot air and Cryptococcus laurentii. Postharvest Biologyand Technology, 117, 177-186. https:// doi.org/10.1016/j.postharvbio.2016.03.001

Wei, Y., Zhou, D., Wang, Z., Tu, S., Shao, X., Peng, J., Pan, L. \& $\mathrm{Tu}, \mathrm{K}$. (2018). Hot air treatment reduces post-harvest decay and delays softening of cherry tomato by regulating gene expression and activities of cell wall-degrading enzymes. Journal of the Science of Food and Agriculture, 98(6), 2105-2112. https://doi.org/10.1002/jsfa.8692

Xie, G., Tan, S. \& Yu, L. (2012). Morphological and molecular identification of pathogenic fungal of post-harvest tomato fruit during storage. African Journal of Microbiology Research, 6(22), 4805-4809. https://doi.org/10.5897/ AJMR12.596

Xing, Y., Xu, Q., Li, X., Chen, C., Ma, L., Li, S., Che, Z. \& Lin, H. (2016). Chitosan-based coating with antimicrobial agents: Preparation, property, mechanism, and application effectiveness on fruits and vegetables. International Journal of Polymer Science, 2016 1-24. https://doi. org/10.1155/2016/4851730

Yan, L., Zheng, H., Liu, W., Liu, C., Jin, T., Liu, S. \& Zheng, L. (2021). UV-C treatment enhances organic acids and GABA accumulation in tomato fruits during storage. Food Chemistry, 338, 128126. https://doi.org/10.1016/j. foodchem.2020.128126

Yasser, M. M., Marzouk, M. M., Kamel, T. A. \& Naaffa, A. M. A. (2019). Effect of hot water treatment on post-harvest fruit rots and quality of tomato fruits. Plant Archives, 19(2), 2325-2334.

Youssef, K., Sanzani, S. M., Ligorio, A., Ippolito, A. \& Terry, L.A. (2014). Sodium carbonate and bicarbonate treatments induce resistance to post-harvest green mould on citrus fruit. Postharvest Biology and Technology, 87, 61-69. https:// doi.org/10.1016/j.postharvbio.2013.08.006

Zhang, W. \& Jiang, W. (2019). UV treatment improved the quality of post-harvest fruits and vegetables by inducing resistance. Trendsin Food Science \& Technology, 92, 71-80. https://doi.org/10.1016/j.tifs.2019.08.012

Zhang, X., Sheng, J., Li, F., Meng, D. \& Shen, L. (2012). Methyl jasmonate alters arginine catabolism and improves postharvest chilling tolerance in cherry tomato fruit. Postharvest Biology and Technology, 64(1), 160-167. https://doi. org/10.1016/j.postharvbio.2011.07.006

Zong, Y., Liu, J., Li, B., Qin, G. \& Tian, S. (2010). Effects of yeast antagonists in combination with hot water treatment on postharvest diseases of tomato fruit. Biological Control, 54(3), 316-321.https://doi.org/10.1016/j.biocontrol.2010.06.003 